\title{
Arte(Fatos): Silvio Nunes Pinto
}

\author{
Sainy C. B. Veloso*
}

http://dx.doi.org/10.22409/poiesis.1829.113123

\begin{abstract}
RESUMO: A investigação contempla a obra de Silvio Nunes Pinto, trabalhador rural que, no exercício de suas atividades cotidianas e para atender às demandas de suas realidades concreta e psíquica, produziu objetos ricos em detalhes e acabamentos, apesar de não se restringir somente às funções a elas destinadas. Sua obra é regida pelo modelo de fabricação que dá forma à matéria, indistinta do doméstico e do político. A "diferença política" de seu fazer em interação com os demais outros à sua volta, principalmente com o casal de artistas Vera Barcellos e Patrício Farias, possibilitou-lhe configurar um espaço para fazer, ver, nomear, na "partilha do sensível". (RANCIÈRE, 2005)

PALAVRAS-CHAVE: política, arte, recepção

ABSTRACT: The research contemplates the work of Silvio Nunes Pinto, a rural worker who, in the exercise of his daily activities and to meet the demands of his concrete and psychic realities, produced objects rich in details and finishes, nevertheless, not only functions. His work is governed by the manufacturing model that gives form to matter, indistinct from the domestic and the political. The "political difference" of his interaction with the others around him, especially with the couple of artists Vera Barcellos and Patrício Farias, allowed him to create a space to do, to see, to name, in the "sharing of the sensible". (RANCIÈRE, 2005)
\end{abstract}

KEYWORDS: politics, art, reception

\footnotetext{
* Sainy C. B. Veloso é doutora em História Cultural pela UnB, com pós-doutorado em Cultura y Sociedad na Universidad de San Martín, em Buenos Aires. Graduada em Educação Artística; especialista em Linguagens Artísticas e mestra em Artes. É professora da Universidade Federal de Goiás - UFG, na FAV e no Programa Interdisciplinar (Mestrado e Doutorado) em Performances Culturais/ FCS. E-mail: sainyveloso@yahoo.com.br
} 


\section{O artista, a arte, 0 tempo, o espaço}

A arte elege o artista pela força de sua potência. Força vital, psíquica, em ficção com a materialidade de sua carne efêmera. Muito antes da constituição do pensamento, da consciência, da ação, o eleito sabe - sem saber - da inevitabilidade do destino humano: morrer. Subjugado à constante produção de sentido, de subjetividades e recriação de coisas, ações, acontecimentos, tenta superar seu drama. Tentativa de vencer a morte?

Nesse sentido, Georges Didi-Huberman, em O que vemos, o que nos olha, constrói uma crítica a partir da tautologia do minimalismo norte-americano (o que vemos), dialeticamente com o que nos olha: a ausência, o vazio, diante de um destino inevitável, a morte. O que nos olha é, portanto, o campo simbólico. Aí se instala a arte que, na angústia diante da falta de sentido, assume formas de suturas parciais.

Ao mesmo tempo em que o artista partilha de rituais comuns - coisas, ações, acontecimentos - retira-as de seus lugares, não satisfeito com o comum de seus lugares, para, novamente, por meio de uma política sensível (RANCIÉRE, 2005), reapresentá-las em compartilhamento, nos recortes de realidades externas que delineiam espaços e tempos anacrônicos.

É na dinâmica do devir que o tempo atualiza essas existências potenciais. Antes de se materializar em intenção ou produto, essa potência corre encarnada no corpo - no sentido não consciente - para, no transcurso do tempo, posicionar o eleito em espaços liminares, sujeitos da apreensão de sua incompletude e inadequação no mundo. O tempo é, pois, o ardor vivificador dos desejos que, ao mesmo tempo, altera o espaço, dando-lhe novos sentidos.

Arnold Van Gennep (1977) formulou o conceito de liminaridade como uma fase peculiar na sequência padronizada dos rituais de passagem. Contudo, Victor Turner (1974), por meio dos atributos simbólicos constitutivos de tais rituais, compreendeu a liminaridade como uma das possíveis manifestações da communitas: uma forma de relacionamento humano primordial, contrária à forma estruturada e hierarquizada de relacionamentos demarcados por posições e papéis sociais. Assim, a communitas propiciam espaços paradoxais, dinâmicos, pois não são centrais nem marginais, mas constitutivos de movimentos atemporais em realidades psíquicas. Igualmente, a potência da arte se realiza no trânsito entre espaços instituídos e, paradoxalmente, deles distantes, não obstante seus produtos acabarem neles presentes como nos museus ou galerias de arte. 
Isto não dá ao eleito um privilégio ontológico. É somente outra maneira de olhar, sentir e viver o mundo com a força da potência psíquica de seu corpo, em seu tempo. Talvez seja isso o que move e diferencia o artista dos demais indivíduos. Criar communitas, embora quase nunca se realize como tal, pois que intrinsecamente dinâmica, retroalimenta o artista, uma vez que é dela que provêm os processos e possibilidades de ordenações. Um processo de troca, que ao se realizar no espaço social, nele se desenvolve historicamente, sem se separar do espaço histórico em constante transformação. (BAKHTIN, 1990, p. 358)

A exposição de um objeto artístico, por exemplo, é uma forma de communitas, na qual e pela qual todos comungam em "interação face-a-face" (GOFFMAN, 2011[1959]) no espaço público, na apreciação do objeto artístico. Desse modo, o objeto, a princípio, organiza em torno de si, mesmo que temporariamente - e talvez até por esse mesmo motivo -, indivíduos que não se relacionam, a princípio, de maneira estruturada e hierarquizada de posições e papéis sociais.

Penso que a noção de cronotopo (BAKHTIN, 1990) - composição das palavras gregas cronos: tempo e topo: lugar - clareia bem essa relação espaço-tempo. Ainda que o autor use este conceito no âmbito literário, cronotopo constrói a imagem do indivíduo na interação das relações dos personagens, o que torna concreto o espaço. Assim, o tempo transforma o indivíduo que transforma o espaço, em um movimento dialógico, na interação com o espaço do outro. Movimento que pressupõe abertura e inacabamento, tensão e abertura.

Entendemos então que para o artista há sempre a possibilidade de transgressão. De pensar e de fazer diferente, mesmo no lugar mais comum a ele destinado pelas realidades cotidianas. Falamos da capacidade imaginativa que a força potente da arte comporta em sua dimensão criativa. Essa potência o conduz em direção a uma ética e a uma política, ao mergulhar nas experiências comuns, para delas extrair os desvios necessários aos processos singulares, criativos.

O imaginário é, portanto, a potência criativa individual e/ou coletiva de dar sentido ao mundo. É ela que busca respostas para a angústia existencial no processo de vida, na tensão entre a constituição como sujeito e apreensão do mundo, frente à experiência da passagem do tempo, ao destino inevitável da vida: a morte. Para tal resposta, segundo Gilbert Durand (1989), formamos símbolos na vida sociocultural, oriundos de um conjunto relacional de imagens constelações - que convergem em torno de núcleos organizadores, ou seja, de uma energia psíquica para dar significado a tudo o que existe. 


\section{O artista autodidata: Silvio Nunes Pinto}

Silvio Nunes Pinto era um homem comum, com pouca instrução, sem acesso a exposições, museus, galerias, enfim, sem acesso ao "sistema da arte". (CAUQUELIN, 2005) Como trabaIhador rural, vivia sua vida comezinha em um pedaço de terra no município de Viamão, próximo de Porto Alegre, RS. Ali viveu toda sua vida, em uma pequena casa com aproximadamente $10 \mathrm{~m}^{2}$, construída por ele, perto da casa de sua família.

Silvio viveu 65 anos. Nasceu em 1940, no município de Viamão, e ali morreu em 2005. Segundo a artista Vera Barcellos (2016), ele pertencia a uma família numerosa, trabalhou no campo, foi jogador de futebol amador em dois clubes e não teve a oportunidade de concluir uma educação formal. A artista conta que Silvio começou sua obra artística na década de 1960 e não se sabe o que a determinou.

Fato é que Silvio, em um dado momento de sua vida, começou a produzir objetos, funcionais ou não, de maneira artística. Não podemos cronologicamente precisar uma data para tal fato, pois não há registros dos mesmos. Neles deixa transparecer nos detalhes, em seus acabamentos e criatividade, uma maneira singular de ser e pensar o mundo.

Sua existência se entrecruza com a de Vera Barcellos e seu marido, o escultor chileno Patrício Farias, quando ambos passaram a morar na chácara do casal e nela construíram seu ateliê. Ali, já se encontravam a propriedade de Sílvio e a de sua família. Por certo, Silvio se reconheceu na atividade artística de ambos, na vontade da arte e força de sua potência. Assim, encontrou em Vera e Farias a legitimação da "autoridade" (CERTEAU, 1995) para seu processo criativo, não obstante ambos não soubessem de suas obras. Mas são necessários, conforme afirma Michel de Certeau (1995, p. 34), para toda vontade construtiva, "sinais de reconhecimento e acordos feitos acerca das condições de possibilidade, para que seja aberto um espaço onde se desenvolva".

Inter-relacionam, nesse processo, autoridade e política quando interdita ou possibilita condições novas em seus acordos, por vezes nem sempre muitos claros e conscientes. Nesse sentido, Silvio não traz em suas obras referências das obras de Vera ou/e de Farias - não das obras que provavelmente via cotidianamente -, mas encontra legitimação da autoridade no fazer artístico em sua relação com o casal. 


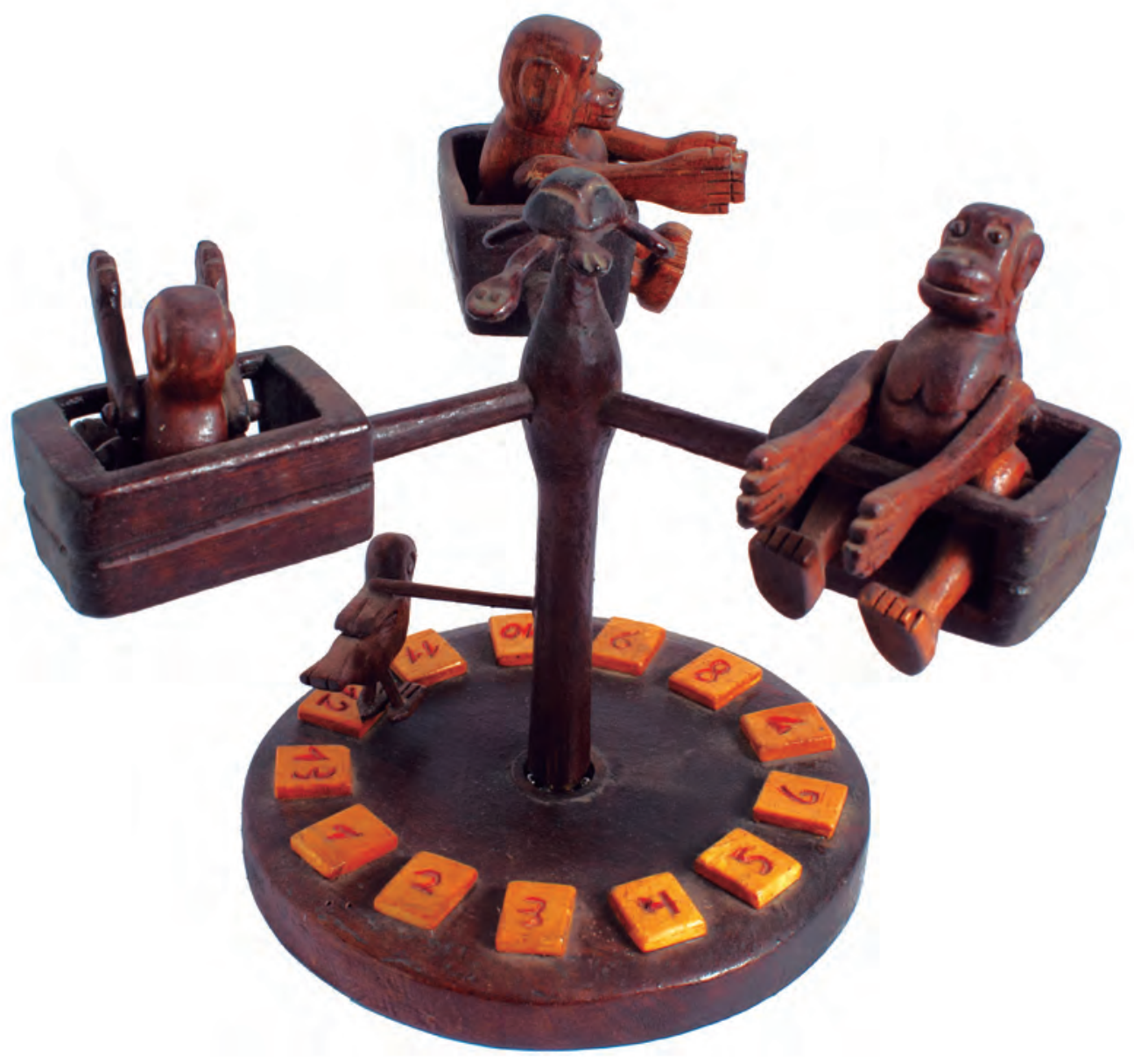

Acervo Artístico Fundação Vera Chaves Barcellos 
Desse modo, contaminado pelo espaço/tempo dessa convivência, deu vazão à demanda da potência da arte para criar um modo específico de agir, subjetivamente e racionalmente, de acordo com que lhe era próprio e com o que tinha disponível.

A política, então, não é o exercício do poder entendido como prática do fazer, mas na forma da relação de um sujeito com os outros e o mundo, conforme entende Jacques Rancière (2012). Para o autor, a política não nasce da necessidade humana de um grupo de seres humanos vivendo em sociedade. Ela é um "acidente" quando instaura a "diferença política" (RANCIÈRE, 2012, p. 66) e se define pela participação em coisas contrárias: um trabalhador rural que faz surgir sua expressão criativa de maneira muito particular e, pela qual, configura um espaço para ver, criar e nomear, na "partilha do sensível". (RANCIÈRE, 2005) Percebemos, então, nas ideias do autor, que o trabalho da política é a configuração do seu próprio espaço ao dar a ver ao mundo seus sujeitos e suas operações. Assim, dissolve a diferença imposta pelas formas de dominação social historicamente constituídas.

Após a morte de Sílvio, Vera tomou contato com a "com a "diversidade" e "riqueza de imaginário" de sua obra (BARCELLOS, 2016) ao entrar em sua pequena casa de madeira. Temendo eventual dispersão do conjunto de obras, ela propôs a aquisição de todas as peças, as quais constituíram uma exposição e foram incorporadas ao acervo da Fundação que recebe seu nome.

\section{A obra, o tempo e o espaço}

Conheci os arte[fatos] de Silvio, em 2016, na mostra Silvio Nunes Pinto: Ofício e Engenho, organizada por Marcela Tokiwa e Vera Chaves Barcellos, na Fundação Vera Chaves Barcellos, em Viamão, Porto Alegre. Naquele instante, a palavra arte[fatos] me pareceu a mais adequada aos seus objetos. Ela corresponde a um produto do imaginário fruto de um rico "trajeto antropológico". (DURAND, 1989)

Esse termo, criado por Durand, corresponde a um percurso no qual há uma troca incessante entre as pulsões subjetivas e as intimações objetivas, os fatos que nos demandam na realidade concreta. O trajeto é moldado por um movimento dinâmico e organizador, com expressões de interações múltiplas, além de ser representado por um objeto que se deixa moldar com a reversibilidade dos imperativos pulsionais do sujeito. 


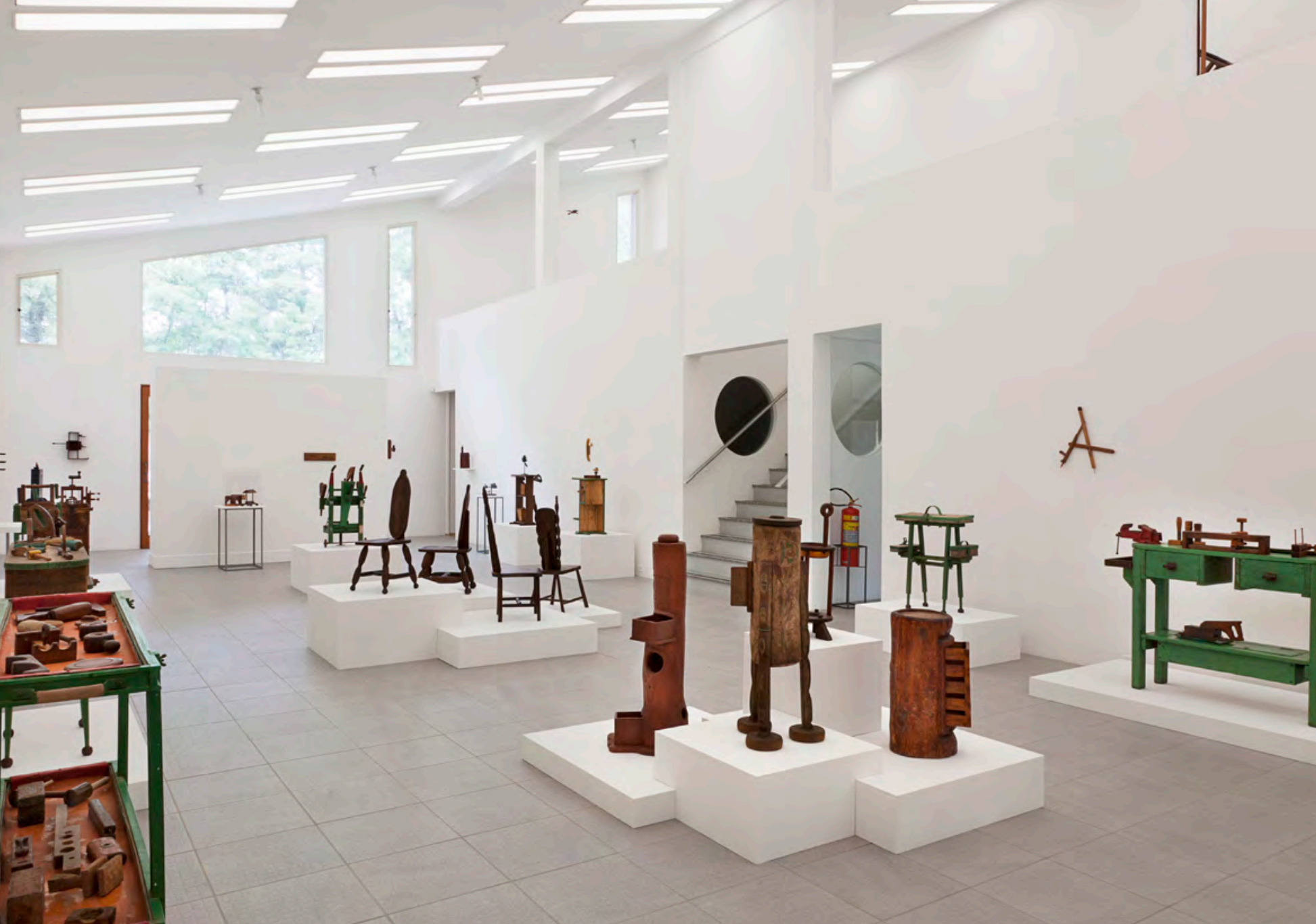

Foto: Leopoldo Plentz 
Desse modo, esta palavra não corresponde a artefatos, objetos funcionais construídos por um habilidoso artesão. Mas a objetos criados no campo simbólico, com um excelente e cuidadoso acabamento de artífice, próprio de quem sente prazer em realizá-los, no limitado espaço de sua casa que exigiu compactuar as coisas. São objetos auxiliares ou inúteis às atividades cotidianas de jardineiro, organizacionais de fatos da vida cotidiana de Sílvio, que ultrapassam suas funcionalidades para fazer suturas parciais em sua relação eu-mundo. Assim, compreendo sua obra como produtos originários de fatos - reais e psíquicos - que lhe demandaram representações visuais, relacionados às suas questões existenciais.

Em uma das paredes de sua pequena casa havia manchetes e imagens em jornais e revistas - não datadas e sem fontes - de um desfile cívico com jovens carregando a bandeira brasileira; uma imagem do cantor negro norte-americano Sammy Davis Junior (1925-1990) com a legenda "Agora eu tenho domínio dos meus músculos, faço o que eu quero do meu corpo"; a imagem de Martha Vieira Figueiredo Cunha, a Martinha (1949-), cantora brasileira; e a imagem de um encontro entre Roberto Carlos (1941-), Erasmo (1941-) e Carlos Imperial (1935-1992), com a legenda "Roberto Carlos, Erasmo Carlos e Carlos Imperial continuam a se reunir normalmente (ao alto) e as fãs (embaixo) são um estímulo." As fotos estão em uma moldura triangular, em forma de flâmula, reaproveitada por Silvio.

As imagens correspondem a fatos episódicos - em manchete midiática - que sugerem associações com temáticas por ele desenvolvidas em objetos artísticos, como uma série de veículos militares: Tanque de guerra (07/10/1990); Helicóptero (29/07/1992); Avião de guerra (06/03/1991); Jipe de guerra (02/08/1992); Militar (05/1992); Barco de guerra (13/03/1991). Representam a força de defesa de nosso país, em um suposto desfile cívico?

A teoria do imaginário de Durand (1989) é formulada em torno de um método convergente, no qual os símbolos se (re)agrupam ao redor de núcleos organizadores, as constelações. Estas são estruturadas por isomorfismos, os quais se referem à polarização das imagens e sugerem que há estreita relação entre os gestos do corpo e as representações simbólicas. Os símbolos constelam porque são desenvolvidos de um mesmo tema arquetípico, portanto, variações de uma imagem primeira. Assim é que a obra de Silvio se agrupa em uma produção de objetos militares, peças utilitárias de mobiliário como cadeiras esculpidas, mesas, estantes, armários, luminárias; objetos de uso pessoal, como abotoaduras, pingentes de madeira; figuras do mundo rural: esculturas de animais, pássaros e mamíferos, pequenas esculturas de figuras humanas; equipamentos e instrumentos utilizados em seu ofício de trabalhador rural. 


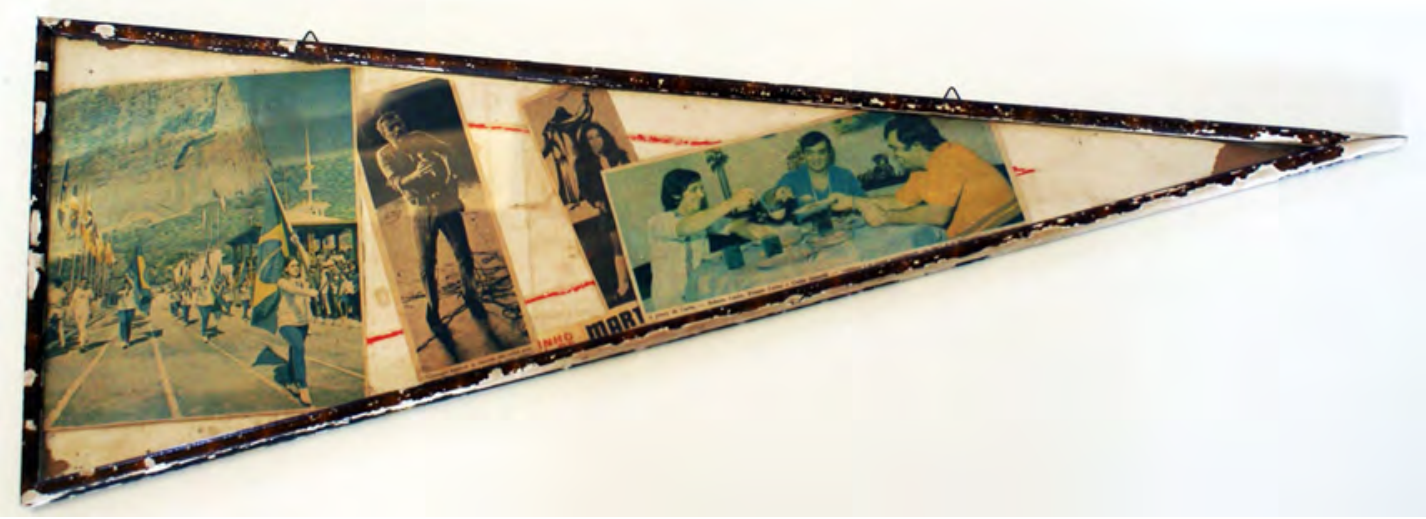

Acervo Artístico Fundação Vera Chaves Barcellos

\section{Arte[fatos]}

Não percebo as obras do artista em categorias diferentes, com propostas intencionais distintas: objetos utilitários e não utilitários, arte, e/ou design. Silvio produz arte com liberdade criativa e dá vazão à sua potência sem que seu pensamento seja dissociado da vida cotidiana e categorias propostas pelo campo da arte. O que ele consome - os fatos cotidianos -, the consome em representações criativas. Esta é a política definida por si mesma. Um modo de agir específico, que depende de uma racionalidade e subjetividade que lhe são próprias.

É nessa relação política que podemos pensar a lógica peculiar e anônima de Sílvio artista e não o inverso. Sua política é fazer - como agente de uma ação - sobre uma matéria e, paradoxalmente, se fazer por meio dela. Desse modo, pensa Rancière (2012), a política como um tipo de ação paradoxal. O artista é criador e é - por sua obra - recriado em e com toda sua humanidade. Talvez seja este o destino da arte: não vencer a morte, não sublimar a vida por um deus transcendente. Mas realizar-se em um corpo que age, pensa e sofre o seu próprio pathos, o trágico de seu drama solitário em um mundo absurdo. 
A política da arte cada vez mais abarca somente o profano e o prosaísmo do mundo. Como tal, os arte[fatos] de Sílvio não foram assentados em bases míticas e poéticas, como instância de contato com a totalidade. Eles não unificam os seres humanos em torno de si para reforçar o reconhecimento da própria humanidade diante de um deus eterno e de uma verdade absoluta. O artista, em seu micro espaço de $10 \mathrm{~m}^{2}$, organiza seu mundo produtivo de maneira que os instrumentos de trabalho e objetos que expressam sua percepção tenham vida orgânica e caibam nesse espaço pensado funcionalmente. Silvio apresenta fragmentos, cacos do mundo reordenados desde a concepção ou planejamento de seus objetos, na diversidade de seus temas, até na ausência de sentido universal.

Por suposto, sem o olhar/reconhecimento de Vera Barcellos, sua obra não mais existiria. A "partilha do sensível" - estética, política e comunicacional - foi fundamental para que se efetivasse a transformação dos "objetos banais" em obras de arte. A linguagem da arte é complexa e "é ferramenta epistemológica: determina o fazer, a apresentação e a recepção da arte". (MELENDI, 1999, p. 43). Ainda que Silvio tenha se balizado em experiências da realidade, o peso maior recaiu na função simbólica do meio.

Suas obras são contraditórias e dialéticas, pois herméticas e abertas a novos sentidos. Ao rés do chão, a arte de Sílvio conquista sua autonomia, sua liberdade criativa desvinculada dos limites da indústria cultural, embora nela incluído. Diferentemente do pensamento de Nicholas Brown (2012) de que o momento é de subsunção real ao capital e o que há é um campo totalizado de mercado e cultura, a produção de Sílvio não serve nada além de si mesma. Aquém da história da arte, ele fabrica sua história. Aquém do sistema da arte, cria seus objetos e procedimentos. A transgressão reside em sua ruptura com a distribuição dos lugares e enunciações instituídas, em redesenhar o espaço e o tempo das coisas comuns para servir às potencias da vida, do imaginário e das necessidades humanas.

\section{Referências}

BARCELLOS, Vera. Sílvio Nunes Pinto. Folder da exposição Silvio Nunes Pinto: Ofício e Engenho. 2016. Disponível em http://fvcb.com. br/?page_id=346. Acesso em 9 abr. 2017.

BAKHTIN, Mikhail. Questões de literatura e de estética: a teoria do romance. Tradução de Aurora Fornoni Bernadini et al. São Paulo: Hucitec, 1990, p. 211-362. 
BROWN, Nicholas. The Work of Art in the Age of Its Real Subsumption under Capital, 2012. Site NONsite Org. Disponível em http:// nonsite.org/editorial/the-work-of-art-in-the-age-of-its-real-subsumption-under-capital. Acesso em 16 jun. 2017.

CAUQUELIN, Anne. Arte contemporânea: uma introdução. São Paulo: Martins Fontes, 2005.

CERTEAU, Michael de. A invenção do cotidiano: 1, Artes de fazer. Petrópolis: Vozes, 1995.

DIDI-HUBERMAN, Georges. O que vemos, o que nos olha. São Paulo: Ed. 34, 2005.

DURAND, Gilbert. As estruturas antropológicas do imaginário. Tradução de Hélder Godinho. Lisboa: Editorial Presença, 1989.

DURAND, Gilbert. A imaginação simbólica. Tradução de Eliane Fittipaldi Pereira. São Paulo: Cultrix / Editora da Universidade de São Paulo, 1988.

GOFFMAN, Erving. A representação do eu na vida contemporânea. Tradução de Maria Célia Santos Raposo. Petrópolis: Vozes, 2011[1959].

MELENDI, Maria Angélica. A linguagem não é transparente. In MELENDI, Maria Angélica. A imagem cega. 1999. Tese (Doutorado) FALE, UFMG, 1999.

RANCIÈRE, Jacques. A partilha do sensível. Tradução de Mônica Costa Netto. São Paulo: EXO experimental org.; Ed. 34, 2005.

RANCIÈRE, Jacques. O espectador emancipado. São Paulo: WMF; Martins Fontes, 2012.

VAN GENNEP, Arnold. Os ritos de passagem. Petrópolis: Vozes, 1977 [1909]. 